\title{
Role of divalent ions, temperature, and crude oil during water injection into dolomitic carbonate oil reservoirs
}

\author{
Mohammad Fattahi Mehraban ${ }^{1,2}$, Shahab Ayatollahi ${ }^{3}$, and Mohammad Sharifi, ${ }^{1, *}$ \\ ${ }^{1}$ School of Petroleum Engineering, Amirkabir University of Technology, Tehran, Iran \\ ${ }^{2}$ Centre for Enhanced Oil Recovery and CO2 Solutions, Heriot-Watt University, EH14 4AS Edinburgh, UK \\ ${ }^{3}$ School of Chemical and Petroleum Engineering, Sharif University of Technology, Tehran, Iran
}

Received: 6 August 2018 / Accepted: 14 January 2019

\begin{abstract}
Although wettability alteration has been shown to be the main control mechanism of Low Salinity and Smart Water (LS-SmW) injection, our understanding of the phenomena resulting in wettability changes still remains incomplete. In this study, more attention is given to direct measurement of wettability through contact angle measurement at ambient and elevated temperatures $\left(28^{\circ} \mathrm{C}\right.$ and $\left.90^{\circ} \mathrm{C}\right)$ during LS-SmW injection to identify trends in wettability alteration. Zeta potential measurement is utilized as an indirect technique for wettability assessment in rock/brine and oil/brine interfaces in order to validate the contact angle measurements. The results presented here bring a new understanding to the effect of temperature and different ions on the wettability state of dolomite particles during an enhanced oil recovery process.

Our observations show that increasing temperature from $28^{\circ} \mathrm{C}$ to $90^{\circ} \mathrm{C}$ reduces the contact angle of oil droplets from 140 to 41 degrees when Seawater (SW) is injected. Besides, changing crude oil from crude-A (low asphaltene content) to crude-B (high asphaltene content) contributes to more negative surface charges at the oil/ brine interface. The results suggest that the sulphate ion $\left(\mathrm{SO}_{4}^{2-}\right)$ is the most effective ion for altering dolomite surface properties, leading to less oil wetness. Our study also shows that wettability alteration at ambient and elevated temperatures during LS-SmW injection can be explained by Electrical Double Layer (EDL) theory.
\end{abstract}

\section{Introduction}

Over the last 10 years, a great deal of research has been conducted to clarify the effect of ion species and injection water salinity on ultimate oil recovery [1-4]. Laboratory studies and field experiments have shown that ultimate oil recovery from sandstone reservoirs can be increased when the salinity of injection water is decreased or the injection water composition is manipulated using divalent ions [5-18]. However, Low Salinity Effect (LSE) in carbonates and the underlying mechanisms leading to trapped oil mobilization have been less investigated compared with sandstones.

In every waterflooding stage across the world, the salinity of injection water is different and depends mainly on the nearby water resource, which varies from one field to another. For example, Persian Gulf seawater is used for waterflooding the Iranian and Arabian oil fields, while North Sea water is typically considered for the waterflooding of Northern fields. Furthermore, produced water, recognized as wastewater, and aquifer water are often injected into oil reservoirs. Variations existing in the concentrations of monovalent and divalent ions in the injection fluid can

\footnotetext{
* Corresponding author: m_sharifi@aut.ac.ir
}

cause rather complex chemical interactions between not only the injection fluid and reservoir minerals, but also the injection fluid and crude oil phase. Some of the divalent ions are called Potential-Determining Ions (PDIs). PDIs are more reactive towards rock surfaces, so that they can adhere to the rock surface and directly affect rock surface charges.

In general, injection water chemistry can be adjusted in order to reach a desired wettability state towards more oil recovery. The adjustment of water chemistry can be conducted either by diluting the injection water, which is called Low Salinity Water (LSW), or by changing the concentration of effective divalent ions, such as Sulphate ions $\left(\mathrm{SO}_{4}^{2-}\right)$, Magnesium ions $\left(\mathrm{Mg}^{2+}\right)$, and Calcium ions $\left(\mathrm{Ca}^{2+}\right)$, which produces what is called Smart Water $(\mathrm{SmW})$. The contribution of this study to this area of water chemistry adjustment lies in the improved understanding of how wettability changes occur in carbonate oil reservoirs and which of the ions included in this study is most responsible for that process.

Carbonate reservoirs are the main focus of this research because incremental oil recovery in carbonates are not yet well explored. In addition, most of the oil left behind in carbonate oil reservoirs occurs principally because of the 
oil-wet nature of these reservoirs. Several laboratory studies have shown a positive LSE in carbonates [1, 19-21] however, there are only a few cases demonstrating a negligible LSE $[22,23]$. Traditionally, the LSE has been investigated through coreflooding and spontaneous imbibition experiments illustrating further oil recovery [19-21, 24-34]. In addition, the LSE has been studied through other experimental means such as contact angle measurement [35], nuclear magnetic response [36] and a very limited amount of experimental work on zeta potential/surface charges [37-39]. Therefore, this study discusses the LSE in dolomite reservoirs by continuously observing the contact angle of oil droplets and measuring the surface charges of dolomite particles in different $\mathrm{SmW}$ receipts.

The principal differences in this work compared with previous studies are as follows:

- The effect of individual divalent ions through contact angle and zeta potential measurements is evaluated at fixed ionic strength.

- The effect of temperature on dolomite surface charges through zeta potential measurements is systematically investigated.

- The effect of crude oil physical property such as asphaltene content on the charge of oil/brine interface and the wettability state of dolomite minerals is examined.

The key factor controlling the wettability state of carbonate particles is the stability of the thin brine film coating the particle's surface [40]. The most important parameter in thin brine film when two oil/brine and rock/brine interfaces approach one another and contribute to Electrical Double Layer (EDL) expansion is the disjoining pressure ( $\Pi)$. The concept of $\Pi$ was first introduced by Derjaguin et al. [41]. Disjoining pressure arises from London-van der-Waals forces, $\Pi_{\mathrm{LVA}}$, EDL forces, $\Pi_{\mathrm{EDL}}$, and structural forces, $\Pi_{\mathrm{S}}$, and is defined as:

$$
\Pi=\Pi_{\mathrm{LVA}}+\Pi_{\mathrm{EDL}}+\Pi_{\mathrm{S}} .
$$

Hirasaki [42] extended this concept to wettability states of oil/brine/rock systems through contact angle measurement as a function of the thickness of the thin brine film. Any adjustment to salinity and ion content of injection water generally influences the stability and thickness of the thin brine film and consequently the wettability state of oil/brine/rock systems.

The electrical properties of dolomite/water interface have remained a matter of controversial debate due to the fact that dolomite-surface reactions appear to be more intricate than those involving silicates or even calcites. Besides, the carbonate surface charge can be affected by ionic strength, $\mathrm{pH}$ [37-39], and temperature [43]. In Iranian oil fields, the formation brines are strongly saline, particularly in carbonate formations, hence the rock surface charges are fairly expected to be positive due to the high $\mathrm{Ca}^{2+}$ concentration [44, 45].

PDIs such as $\mathrm{SO}_{4}^{2-}, \mathrm{Mg}^{2+}$, and $\mathrm{Ca}^{2+}$ can significantly affect the interactions at the rock/brine interface which directly influences the EDL in carbonate reservoirs
[27, 37-39, 46]. Increased temperature also plays an important role as it results in an increase in the reactivity of ions towards rock surface. Furthermore, it has been observed that $\mathrm{Mg}^{2+}$ is able to substitute $\mathrm{Ca}^{2+}$ on the carbonate surface at elevated temperatures above $90{ }^{\circ} \mathrm{C}$ [46]. Rao [47] demonstrated that temperature plays a role in determining the wettability state in carbonate reservoirs, since hightemperature carbonate reservoirs turned up to be more water wet in comparison to low-temperature carbonate reservoirs.

The aim of this study is, first, to evaluate the effect of ion content of injection water on wettability alteration and understand how the PDIs can behave differently at higher temperatures. Second, this study tries to gain insight into how crude oil type could influence wettability alteration during SmW and Low Salinity Smart Water (LS-SmW) injection. Finally, an attempt is made to clarify the role of temperature in wettability alteration and whether temperature can make a difference in the performance of PDIs towards dolomite surfaces. To achieve these aims, contact angle measurements were employed at ambient and elevated temperatures for SmWs and LS-SmWs which are reported in the first part of this work. In Section 3.3, the zeta potential measurements of the brine samples used to validate the contact angle results are presented. Finally, all the wettability results acquired in this study are reported in Wettability Shift Index (WSI) format, presented in Section 3.4, because this makes it easier to compare results and allows us to find a more evident relationship regarding the surface charge data.

\section{Material and methods}

\subsection{Brine}

To provide the brine samples in the laboratory, Seawater (SW) and Formation Water (FW) were prepared by combining different amounts of pure salts with deionized water. FW was utilized to soak the rock slices to restore the wettability towards initial wettability state as will be described in Contact Angle section (i.e. Sect. 2.4). SW was prepared based on the composition of Persian Gulf water and FW composition was provided from one of the Iranian oil reservoirs. In Table 1, SW-4S represents seawater four times spiked with sulfate concentration. Three expressions are used in this study to refer to the brines. When the brine salinity is lower than SW, LSW is used, and if the ion content of a brine is different compared with SW, it referred to as $\mathrm{SmW}$, and finally if both ion content and salinity of injection water are changed, the prepared brine is called LS-SmW. All brines were filtered through $0.43 \mu \mathrm{m}$ Millipore filter and vacuumed in order to reduce the dissolved air prior to the tests. The compositions of the utilized brine samples are listed in Tables 1 and 2.

\subsection{Rock characterization}

The rock samples used in this experimental work were obtained from a carbonate outcrop in the southwest of Iran. The following figures show the results of an X-Ray 
Table 1. The composition of SmWs used in this study.

\begin{tabular}{lccccc}
\hline Salt & FW $(\mathrm{ppm})$ & $\mathrm{SW}(\mathrm{ppm})$ & SW-4S $(\mathrm{ppm})$ & SW-4Ca $(\mathrm{ppm})$ & SW-4Mg $(\mathrm{ppm})$ \\
\hline $\mathrm{NaCl}$ & 141314 & 28400 & 11772 & 21859 & 0 \\
$\mathrm{KCl}$ & 628 & 800 & 800 & 800 & 6430 \\
$\mathrm{MgCl}_{2}$ & 2854 & 6430 & 6430 & 5520 & 21862 \\
$\mathrm{CaCl}_{2}$ & 40287 & 1380 & 1380 & 4490 & 1380 \\
$\mathrm{Na}_{2} \mathrm{SO}_{4}$ & 2588 & 4490 & 17959 & 100 & 4490 \\
$\mathrm{NaHCO}_{3}$ & 2011 & 100 & 100 & 39199 & 100 \\
Salinity (ppm) & 189682 & 41600 & 38442 & 0.832 & 28632 \\
Ionic strength (M/L) & 4.220 & 0.832 & 0.832 & 0.832 \\
\hline
\end{tabular}

Table 2. The composition of LSW and LS-SmWs used in this study.

\begin{tabular}{lcccc}
\hline Salt & 10SW $(\mathrm{ppm})$ & 10SW-4S $(\mathrm{ppm})$ & 10SW-4Ca $(\mathrm{ppm})$ & $10 \mathrm{SW}-4 \mathrm{Mg}(\mathrm{ppm})$ \\
\hline $\mathrm{NaCl}$ & 2840 & 1177 & 2186 & 0 \\
$\mathrm{KCl}$ & 80 & 80 & 80 & 80 \\
$\mathrm{MgCl}_{2}$ & 643 & 643 & 643 & 2186 \\
$\mathrm{CaCl}_{2}$ & 138 & 138 & 552 & 138 \\
$\mathrm{Na}_{2} \mathrm{SO}_{4}$ & 449 & 1796 & 449 & 449 \\
$\mathrm{NaHCO}_{3}$ & 10 & 10 & 10 & 10 \\
Salinity (ppm) & 4160 & 3844 & 3920 & 2863 \\
Ionic Strength (M/L) & 0.083 & 0.083 & 0.083 & 0.083 \\
\hline
\end{tabular}

Diffraction test of the rock samples. Figure 1 of the supporting document (sf.1) shows that the majority of the rock samples are dolomite.

\subsection{Crude oil}

Two different crude oil samples were provided from two Iranian oil fields in the southwest of Iran. The physical properties of crude oil samples are shown in Table 3. It is apparent that the main difference in the properties of crude oil samples is their asphaltene content; crude-B (asphaltenic crude oil) contains 30 times more asphaltene compared to crude-A (non-asphaltenic crude oil).

\subsection{Contact angle}

The contact angle of oil droplets on the dolomite surface was measured at ambient and elevated temperatures of $28^{\circ} \mathrm{C}$ and $90{ }^{\circ} \mathrm{C}$, respectively, using Drop Shape Analysis apparatus (sf.2 of supporting document). All contact angle tests were repeated two times in order to check the accuracy of the tests and to minimize the measurement error. The measurement error was almost lower than \pm 5 degrees, which was made possible by the high-resolution images captured by the instrument and low surface roughness of the rock slices which had been polished in the laboratory. To rigorously evaluate wettability alteration processes on
Table 3. Physical properties of used crude oils.

\begin{tabular}{lcccc}
\hline $\begin{array}{l}\text { Crude } \\
\text { oils }\end{array}$ & $\begin{array}{c}\text { Acid } \\
\text { number } \\
(\mathrm{mgKOH} / \mathrm{g})\end{array}$ & $\begin{array}{c}\text { Asphaltene } \\
\text { content } \\
(\%)\end{array}$ & $\begin{array}{c}\text { Density } \\
\left(\mathrm{gr} / \mathrm{cm}^{3}\right)\end{array}$ & $\begin{array}{c}\text { Viscosity } \\
(\mathrm{cP}) \text { at }\end{array}$ \\
\hline Crude-A & 0.14 & 0.20 & 0.84 & 2.35 \\
Crude-B & 0.10 & 6.00 & 0.87 & 3.30 \\
\hline
\end{tabular}

the dolomite surfaces, the following in-house procedure was followed:

1. The rock plates were carefully polished to eliminate surface roughness effects.

2. The polished rock plates were washed in an ultrasonic bath to remove surface contamination.

3. The washed rock plates were subjected to $\mathrm{FW}$ (connate water) for 5 days at $90{ }^{\circ} \mathrm{C}$ in order to restore the initial wettability state.

4. The first contact angle measurement of oil droplets on the treated rock plates was conducted at predetermined temperature conditions and was called the initial contact angle $\left(\theta_{0}\right)$, corresponding to the most water-wet state.

5. Now, the rock plates were aged in the crude oil samples for 14 days to restore the original wettability state. It should be stated that the time needed for the 
rock plates to be restored is totally different from the time a core plug requires. Furthermore, this time period strongly depends on some important parameters such as temperature, connate water salinity, ion content, $\mathrm{pH}$, and the physical properties of the aging crude oil [44].

6. After the aging process, contact angle measurements were performed to check if the rocks were completely restored. The contact angle measurements of oil droplets on the treated dolomite samples were assigned as the original contact angle $\left(\theta_{i}\right)$ which were mostly at oil-wet state.

7. The rock plates were subjected to specific brine solutions and the contact angle of oil droplets was continuously tracked over a period of $360 \mathrm{~h}$. The final contact angle indicated whether the brine could change the wettability state of the rock plates or not.

8. Finally, an index was defined for each brine solution which implied how much the wettability of each rock plate had been altered by each brine solution as follows:

$$
\text { Wettability Shift Index }(\text { WSI })=\frac{\theta_{i}-\theta_{f}}{\theta_{i}-\theta_{o}} .
$$

A WSI close to 0 shows that the brine was not effective enough to shift the wettability of the dolomite samples from a strongly oil-wet state towards a less oil-wet state, while a WSI of 1 demonstrates complete wettability alteration towards a strongly water-wet state.

\subsection{Zeta potential measurement}

Zeta-potential measurements were conducted at ambient and elevated temperatures $\left(28\right.$ and $\left.60{ }^{\circ} \mathrm{C}\right)$ and $\mathrm{pH}$ of 7.5 , by using Nano Zs (red badge) Zen3600 supplied by Malvern. The dolomite powders were acquired by crushing the rock sample into particles with a diameter size of around 40 microns.

The rock suspensions were prepared by mixing the dolomite particles with the brines at the ratio of $1 \%$ wt. In order to measure the zeta potential of the oil droplets, a volume ratio of $1: 5$ was used to emulsify the oil droplets in the brine solutions. After preparing a stable emulsion, the samples were subjected to an ultrasonic bath for around $30 \mathrm{~min}$. The $\mathrm{pH}$ of the emulsions was adjusted to 7.5 by applying $\mathrm{HCl}$ and $\mathrm{NaOH}$ of $0.1 \mathrm{M}$ concentration. The $\mathrm{pH}$ adjustment may be required several times due to buffer characteristics of emulsions. After adjusting the sample's $\mathrm{pH}$, they were stirred using a magnetic stirring device.

The electrophoretic mobility of suspended dolomite particles and oil droplets was measured by the instrument, then the zeta potential was calculated. The electrical field applied to the emulsions/suspensions causes dolomite particles and oil droplets to move towards the electrode. Laser Doppler electrophoresis is employed in calculating the particles' mobility, then the potential is calculated using the Smoluchowski equation [48]. All zeta potential measurements were carried out three times and the average values were reported as final zeta potentials. It should be noted that the measurement error was different for each sample; however, for the best case it was around $\pm 3 \mathrm{mV}$ (for SW and dolomite particles) and for the worst case, it was $\pm 8 \mathrm{mV}$ (for SW-4Ca and dolomite particles).

\section{Results and discussion}

In this study, the effect of ionic content of injection water and temperature on wettability alteration was mainly addressed through contact angle measurement. Hence, in this section, the contact angle data for dolomite samples at ambient $\left(28^{\circ} \mathrm{C}\right)$ and elevated temperature $\left(90^{\circ} \mathrm{C}\right)$, when SmWs and LS-SmWs are used, is presented.

The contact angle results are validated through surface charge evaluations at ambient $\left(28^{\circ} \mathrm{C}\right)$ and elevated $\left(60^{\circ} \mathrm{C}\right)$ temperatures. Finally, the crude oil and temperature effects are discussed in terms of WSI, which is the best tool for comparing the acquired results. This experimental work tries to clarify the role of each divalent ion in wettability alteration during LS-SmW and SmW injection at ambient and elevated temperatures.

\subsection{Effect of divalent ions on contact angle at ambient temperature}

In this section, the effectiveness of PDIs of $\mathrm{SO}_{4}^{2-}, \mathrm{Mg}^{2+}$, and $\mathrm{Ca}^{2+}$ towards wettability alteration of strongly oil-wet dolomite plates were investigated through contact angle measurements. It is worth mentioning in this section that all contact angle measurements were conducted at ambient temperature $\left(28^{\circ} \mathrm{C}\right)$. Figure 1 shows the contact angle of oil droplets of crude-A for the period of $360 \mathrm{~h}$ when $\mathrm{SmW}$ and LS-SmW were injected into the systems. As can be seen in Figure 1a, with a fourfold increase in the calcium and magnesium concentration of SW (i.e. SW-4Ca and SW- $4 \mathrm{Mg}$ ), contact angles decrease from 165 to 119 and 133 degrees, respectively. Furthermore, it is interesting to note that while injecting SW solution could change the contact angle of oil droplets to 140 degrees, the injection of SW-4S (i.e. solution with increased $\mathrm{SO}_{4}^{2-}$ concentration) critically affected the wettability alteration process towards more water wetness, as evidenced by the shift in contact angle from 164 to 102 degrees. Figure 1b shows the impact of ionic content on the wettability alteration during LS-SmWs injection, which is similar to those for SmWs. Once more, $\mathrm{SO}_{4}^{2-}$ is shown to be the most effective ion, as $10 \mathrm{SW}-4 \mathrm{~S}$ is able to alter the wettability of the dolomite samples from strongly oil-wet into strongly water-wet states (i.e., contact angle decreases from 158 to 30 degrees). It is noteworthy that diluting SW by 10 times (10SW) did not contribute to wettability alteration towards water-wet state, although it could change the wettability from strongly oil-wet to less oil-wet state after $360 \mathrm{~h}$. Hence, lowering injection brine salinity (LSW) is not enough to overcome the attractive forces between the dolomite surface and oil droplets. Considering the ionic content of injection water, $\mathrm{SO}_{4}^{2-}$ is potentially the most effective ion in SW which could change the wettability of dolomite particles towards a less oil-wet state. However, it is noticeable from these results, that 


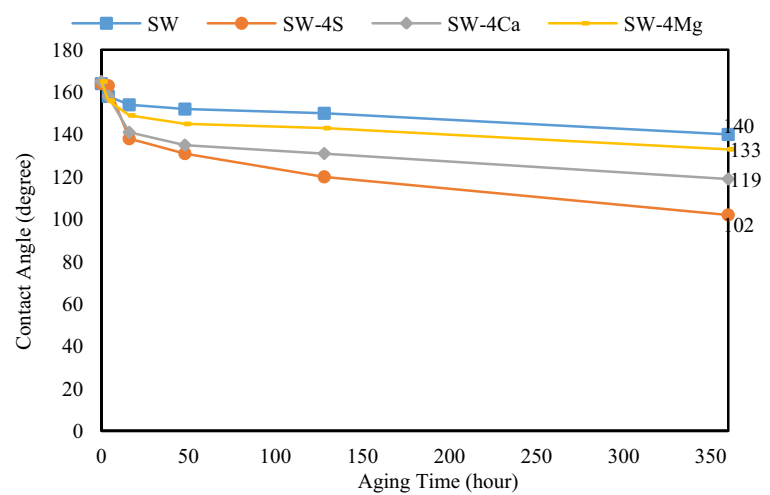

(a)

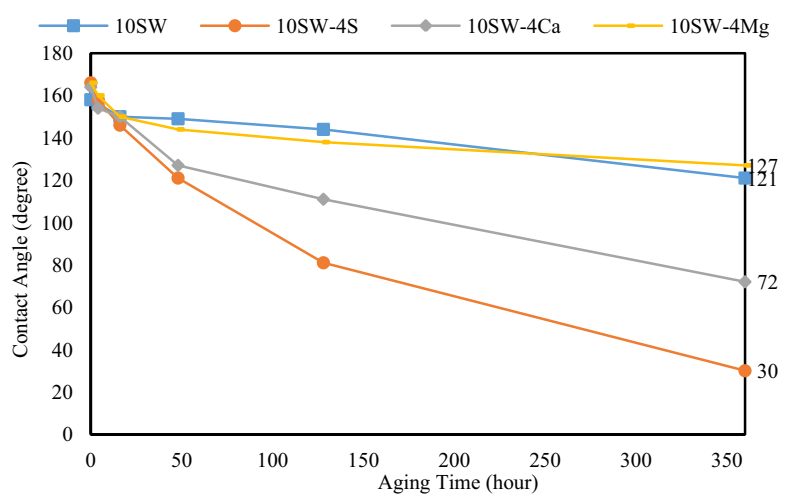

(b)

Fig. 1. Effect of ion content on wettability state of dolomite particles through contact angle measurements at ambient temperature and pressure of $28{ }^{\circ} \mathrm{C}$ and 14.7 psi, crude-A. (a) Adjusted SW composition, (b) adjusted 10SW composition.

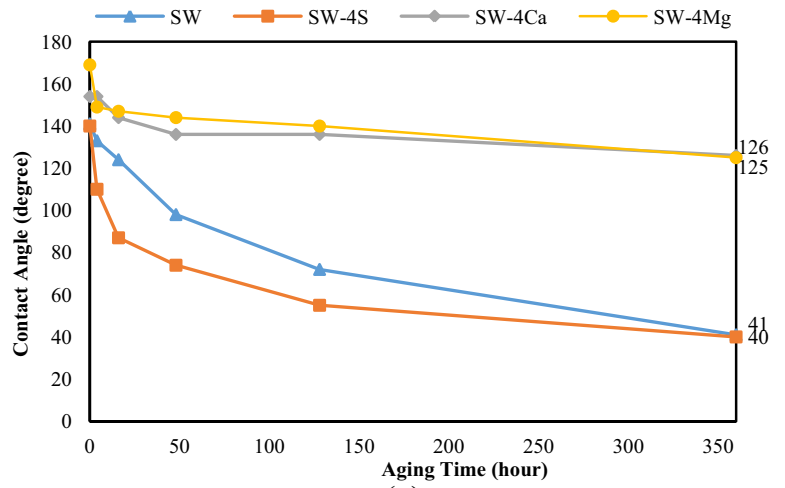

(a)

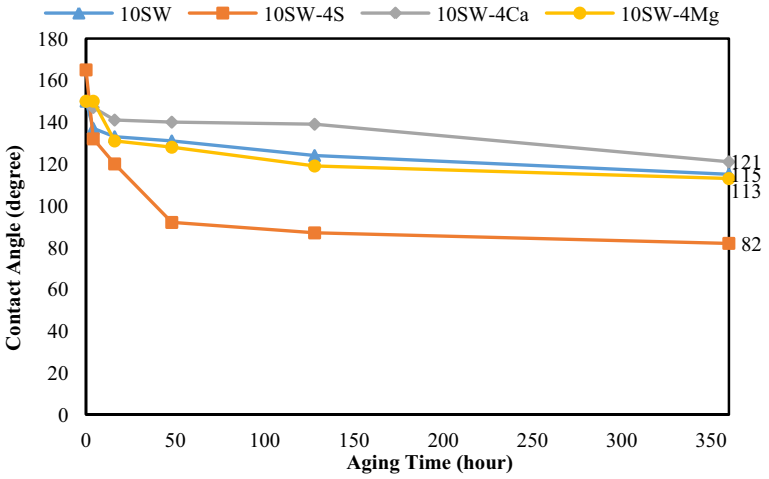

(b)

Fig. 2. Effect of ion content on wettability state of dolomite particles through contact angle measurements at elevated temperature and ambient pressure of $90{ }^{\circ} \mathrm{C}$ and 14.7 psi, crude-A. (a) Adjusted SW composition, (b) adjusted 10SW composition.

adjusting the ion content of injection water for diluted brines (10SW) is much more effective than the high salinity brines, such as SW. While the contact angle change for $10 \mathrm{SW}-4 \mathrm{~S}$ was shown to be around 128 degrees, the change in contact angle of SW-4S was just 62 degrees approximately. The mechanisms behind the wettability alteration achieved by modifying the ion content of injection water will be discussed later in Section 3.3. For the sake of completeness, the results obtained for contact angle measurements of brines with crude-B are provided in the supporting document (Figures sf3). It should be noted that figures in sf3 demonstrate similar effectiveness of $\mathrm{SO}_{4}^{2-}$ in changing the wettability of dolomite particles towards more water-wet states when crude-B is used. All the results obtained, including those for crude-B, are discussed in terms of WSI in Section 3.4.

\subsection{Effect of individual ions on contact angle at elevated temperature}

In this section, the effect of salinity and ion content of injection water on wettability alteration of dolomite particles at the elevated temperature of $90{ }^{\circ} \mathrm{C}$ is shown. Figure 2 demonstrates the contact angle of oil droplets and dolomite particles throughout $360 \mathrm{~h}$ for $\mathrm{SmW}$ and LS-SmW injection at elevated temperature. From Figure 2a, increasing the $\mathrm{SO}_{4}^{2-}$ concentration of SW solution (SW-4S) could shift the wettability of dolomite plates from strongly oil-wet (140 degrees) to strongly water-wet state (40 degrees). Similar to the results obtained at ambient temperature, $\mathrm{Mg}^{2+}$ and $\mathrm{Ca}^{2+}$ ions in high salinity brines (SW-4Ca and $\mathrm{SW}-4 \mathrm{Mg}$ ) were not able to effectively interact with the dolomite surface as they could not considerably change the wettability state. The interesting point that should be highlighted here is that the wettability alteration due to SW injection was extremely considerable at the elevated temperature compared to the ambient temperature (i.e. for elevated temperatures, the contact angle decreased from 141 to 41 degrees after $360 \mathrm{~h}$ ). To find out the reason behind this interesting behavior of the SW solution, zeta potential measurements were performed. These are discussed in more detail in the next section. Figure $2 \mathrm{~b}$ shows that at elevated temperatures, modifying the ionic content of diluted brines (LS-SmWs) is less effective since they were less capable of changing the wettability of dolomite samples at compared with $\mathrm{SmW}$ brines. In addition, reducing the 


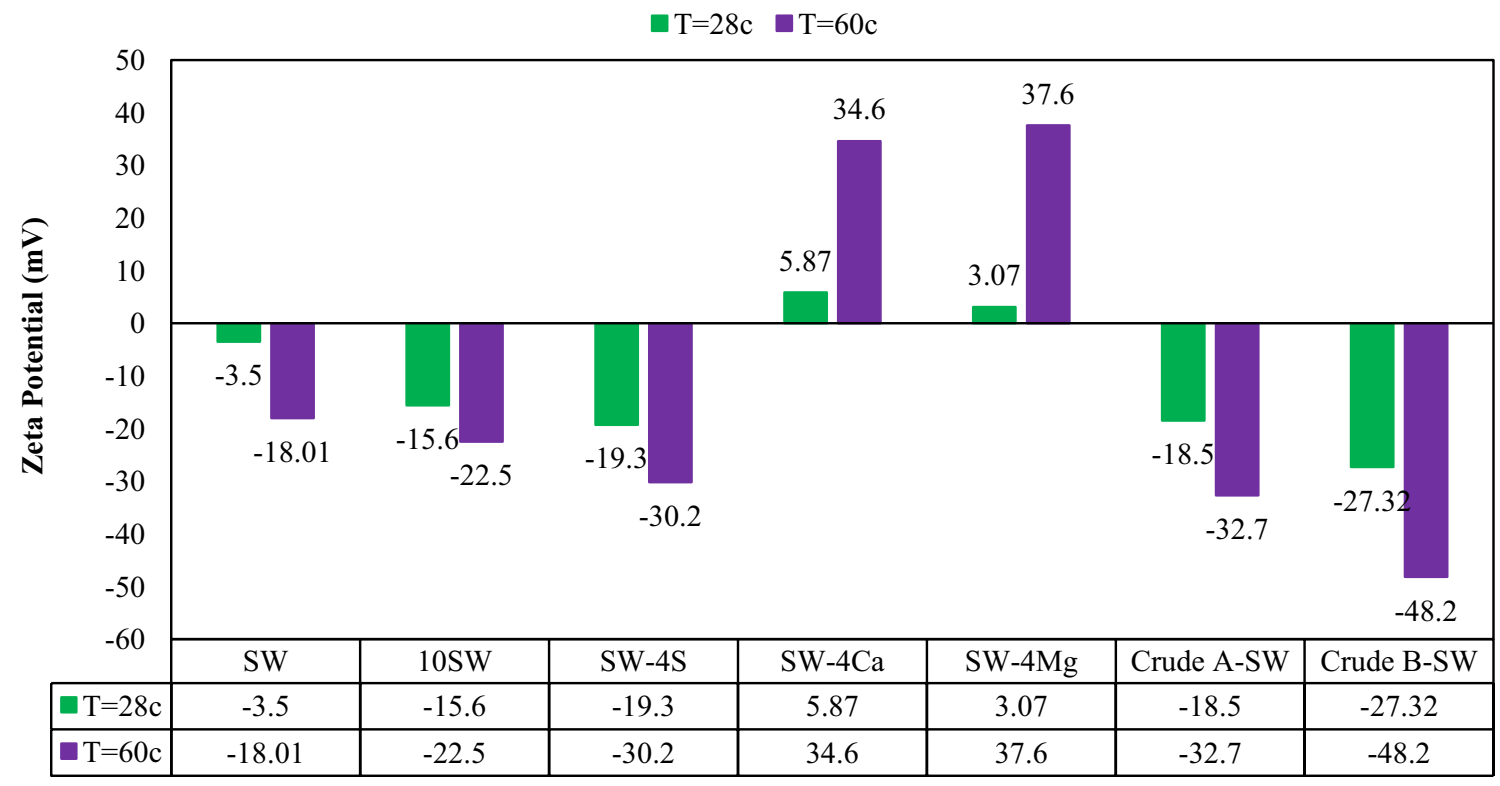

Fig. 3. Zeta-potential of crude oils in SW and dolomite particles emulsified in LSW and different SmW receipts at ambient pressure and $\mathrm{pH}$ of 7.5 .

brine salinity and obtaining 10SW solution, the contact angle shifted from 150 into 115 degrees which is not comparable with the performance of SW at elevated temperature. When LS-SmWs were utilized as injection waters, in the best case, 10SW-4S led to contact angle change from 165 to 82 degrees after $360 \mathrm{~h}$. This shows that although adjusting the ionic content of diluted brines (LS-SmWs) in ambient temperature was fairly effective to change the wettability of dolomite particles, this was not observed at elevated temperature.

\subsection{Surface charges evaluation}

In order to evaluate the effect of each individual divalent ion on the surface charges of dolomite particles and to understand their roles in wettability alteration, the zeta potential of dolomite particles in different ionic waters was measured. Although the interactions at the oil/brine interface were not the main focus of this study, due to the paramount importance of interactions at this interface, a restricted number of electrostatic measurements were conducted. While several researchers have shown that the surface charge of crude oil at a medium range of $\mathrm{pH}$ is negative, we measured the charges of oil droplets to understand to what extent they are negatively charged. It should be added that the zeta potential measurements were limited to an elevated temperature of $60{ }^{\circ} \mathrm{C}$ due to the operating specifications of the Zetasizer device. But, the trends in the measured values helped to provide insight into the effect of temperature on the zeta potential of dolomite and crude oil droplets.

The zeta potential of dolomite particles and crude oil droplets is shown in Figure 3. At ambient temperature of $28^{\circ} \mathrm{C}$, surface charges of dolomite particles in SW, 10SW, and SW-4S aqueous solutions are entirely negative
$(-3.5,-15.6,-19.3 \mathrm{mV}$, respectively), while they are entirely positive when SW-4Ca and SW-4Mg (5.87 and $3.07 \mathrm{mV}$, respectively) are used. The negatively charged surfaces can be explained by the high concentration of $\mathrm{SO}_{4}^{2-}$ in $\mathrm{SW}$ and $\mathrm{SW}-4 \mathrm{~S}$, which results in $\mathrm{SO}_{4}^{2-}$ adsorption and the formation of $\mathrm{CaSO}_{4}^{-}$and $\mathrm{MgSO}_{4}^{-}$complexes at the dolomite surfaces. The negative surface charges at the rock/brine and oil/brine interfaces cause electrostatic repulsion between the interfaces and contribute into more positive disjoining pressure. Hence, when SW, 10SW, and SW-4S aqueous solutions are used as the injection brines, due to EDL expansion, the wettability of the dolomites shifts toward more water wet state that is well in line with the contact angle results.

The positive surface charges of SW-4Ca and SW-4Mg at $\mathrm{pH}$ of 7.5 can be explained by the high concentration of $\mathrm{Ca}^{2+}$ and $\mathrm{Mg}^{2+}$ and the consequent adsorption of $\mathrm{Ca}^{2+}$ and $\mathrm{Mg}^{2+}$ ions onto the dolomite surface through the formation of $\mathrm{CO}_{3} \mathrm{Ca}^{+}$and $\mathrm{CO}_{3} \mathrm{Mg}^{+}$complexes. Moreover, the positive and negative surface charges at the rock/brine and oil/brine interfaces, respectively results in electrostatic attraction leading to negative disjoining pressure. Less disjoining pressure also causes a reduction in thickness of thin film and wettability of the system into oil wet state. Therefore, for SW-4Ca and SW-4 Mg, due to electrostatic attraction between interfaces, the wettability should remain oil wet state that was well approved by contact angle results.

From Figure 3, two distinct trends can be observed in surface charges of dolomite particles and crude oil droplets as influenced by temperature. In one hand, enhancing temperature from $28^{\circ} \mathrm{C}$ to $60^{\circ} \mathrm{C}$ contributes to an increase in negative the surface charges of SW, $10 \mathrm{SW}$, and SW-4S to $-18.01,-22.5$, and $-30.2 \mathrm{mV}$, respectively. The intensity of incremental negative zeta potential for the SW solution is two times that of the 10SW solution. This implies 

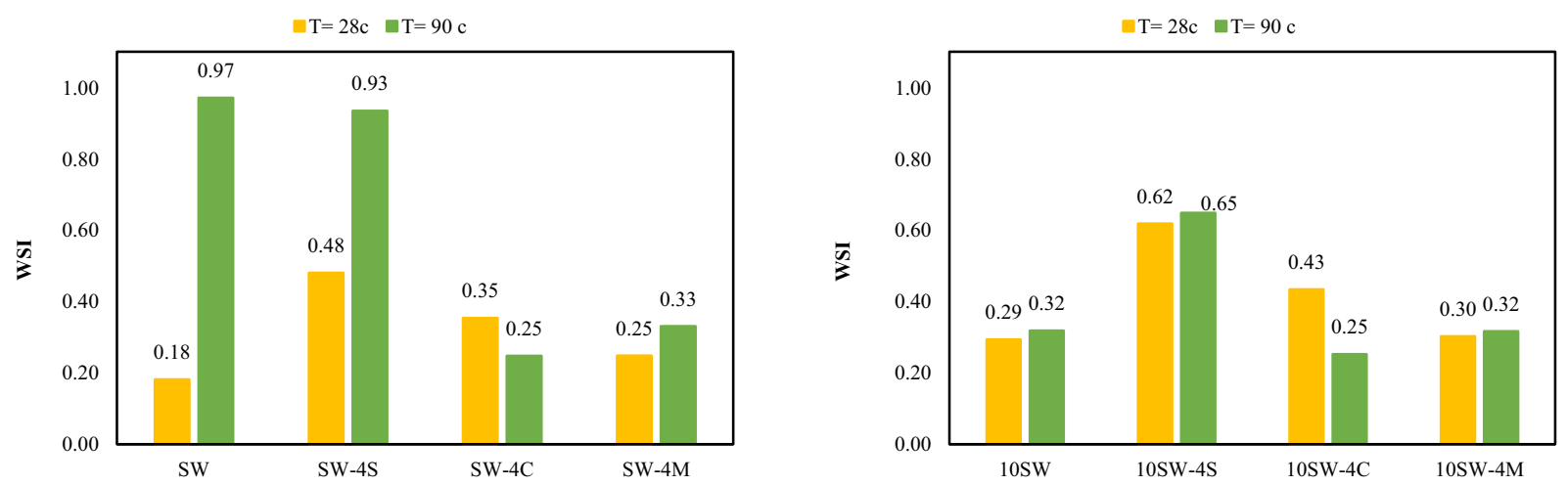

Fig. 4. Effect of temperature on the wettability state of dolomite particles, expressed in terms of WSI, for SmWs and LS-SmWs at ambient and elevated temperatures, and atmospheric pressure.

that the contribution of negative PDIs, such as $\mathrm{SO}_{4}^{2-}$ ions, on surface charges of dolomite particles grows dramatically when temperature increases from $28{ }^{\circ} \mathrm{C}$ to $60{ }^{\circ} \mathrm{C}$. On the other hand, increasing temperature results in a considerable additional positive surface charge for SW-4Ca and SW-4Mg (34.6 and 37.6, respectively) which is due to additional $\mathrm{Ca}^{2+}$ and $\mathrm{Mg}^{2+}$ adsorption onto the dolomite surfaces, at the higher temperature, in forms of $\mathrm{CO}_{3} \mathrm{Ca}^{+}$and $\mathrm{CO}_{3} \mathrm{Mg}^{+}$.

Consequently, in terms of wettability alteration theory, increasing temperature causes an enhancement in PDI's adsorption on the dolomite surfaces. But, wettability state of dolomites depends on the principal PDI in the solution, which for SW solutions turns out to be the $\mathrm{SO}_{4}^{2-}$ ion. That is why in SW, 10SW, and SW-4S solutions the negative surface charges of dolomite particles grew when temperature was increased to $60{ }^{\circ} \mathrm{C}$. On the opposite side, in SW-4Ca and SW-4 Mg solutions which are free of $\mathrm{SO}_{4}^{2-}$, the positive surface charges of dolomite particles grew dramatically at higher temperatures.

Figure 3 also demonstrates that both crude oil samples were negatively charged in SW at ambient temperature (the surface charges of crude-A and crude-B in SW solution were -18.5 and $-27.32 \mathrm{mV}$, respectively). Noteworthy is that crude-B was more negatively charged, which might stem from the different origins of these two crude oil types. It shows that at the same $\mathrm{pH}$, the concentration of deprotonated negatively charged species like carboxylic acids $\left(\mathrm{R}-\mathrm{COO}^{-}\right)$at the oil/water interface is greater for crudeB than crude-A. Although the carboxylic acids can be found in crude oil composition, they are mainly found in the structure of asphaltenes and resins [49].

As temperature was raised from $28^{\circ} \mathrm{C}$ to $60^{\circ} \mathrm{C}$, the zeta potential of crude-A and crude-B shifted towards more negative values of -32.7 and $-48.2 \mathrm{mV}$, respectively. This indicates that increasing temperature leads to more adsorption of deprotonated negatively charged species with low $\mathrm{pk}_{\mathrm{a}}$ such as carboxylic acid into the oil/water interface. Hence, it can be concluded that at higher temperatures, due to higher negative charges at the oil/water interface and the rock/brine interface of SW, 10SW, and SW-4S solutions, the wettability should shift towards a more water-wet state. On the other hand, the wettability should go towards a more oil-wet state for SW-4Ca and SW-4Mg as the surface charges at the rock/brine interface became more positive.

\subsection{Temperature and crude oil effects through WSI evaluation}

In this section, the amount of wettability alteration of dolomite particles due to SmW and LS-SmW injection has been studied through WSI measurement. The aim of this section is to compare different injection water scenarios by assessing the temperature and crude oil effects on the wettability alteration process.

Figure 4 represents temperature effect on wettability alteration during $\mathrm{SmW}$ and LS-SmW injection in dolomitic carbonate rocks. Two clear trends can be observed here. First, as temperature increases, the SmW and LS-SmWs effects become evidently more effective when SW, SW-4SW, SW-4Mg, 10SW, $10 \mathrm{SW}-4 \mathrm{~S}$, and $10 \mathrm{SW}-4 \mathrm{Mg}$ are injected. However, the increases in WSI of SW-4Mg and $10 \mathrm{SW}-4 \mathrm{Mg}$ at elevated temperatures are very small. This can be explained by the zeta potential results (discussed in Sect. 3.3) which showed that the increase in temperature resulted in a critical enhancement in negative surface charges of SW, 10SW, and SW-4S. Furthermore, referring to the zeta potential of crude oil samples in low and elevated temperatures (Fig. 3), it was observed that temperature effect resulted in additional negative surface charges even at the oil/brine interface. Therefore, at the elevated temperatures, when both rock/brine and oil/brine interfaces experience more negative surface charges, the EDL is expanded by more electrostatic repulsion, and rock wettability shifts further towards a strongly water-wet state (Fig. 5a). Second, the wettability indices in Figure 4 also show that the increase in temperature leads to the reduction in the SmW and LS-SmW effects as the WSI decreases from 0.35 and 0.43 at ambient temperature for SW-4Ca and $10 \mathrm{SW}-4 \mathrm{Ca}$, respectively, to 0.25 at elevated temperature. This is not surprising since the zeta potential of SW-4Ca indicated that an increase in temperature leads to more positive surface charges for dolomite at the rock/brine interface. It was also mentioned that the temperature effect resulted in an increase in negative surface charges of oil droplets at oil/brine interface. Hence, at elevated temperature, 
Surface Active Material

Ions in Solution

SW, 10SW, SW-4S, 10SW-4S
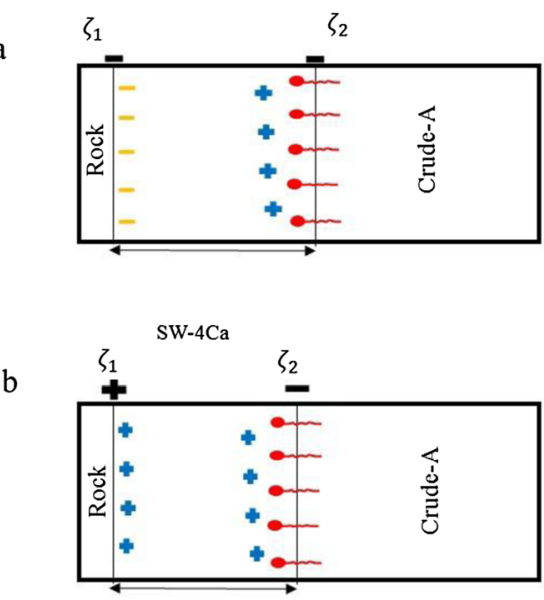
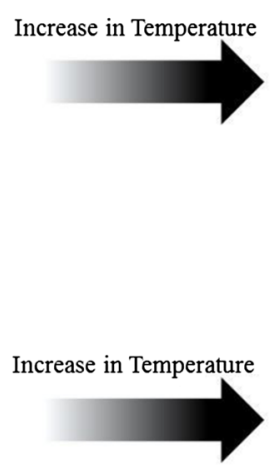

SW, 10SW, SW-4S, 10SW-4S

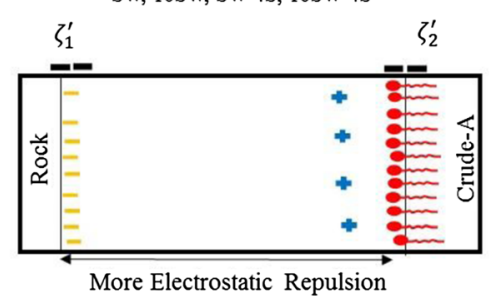

W-4Ca

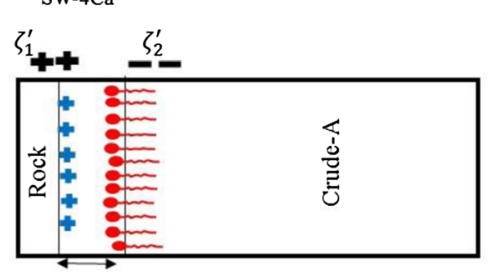

More Electrostatic Attraction

Fig. 5. The mechanism of wettability alteration through water injection, temperature effect (a) Rock is negatively charged in SW, 10SW, SW-4S, and 10SW-4S brines $\left(\zeta_{1}\right)$ and also the charge at the oil/water interface is negative $\left(\zeta_{2}\right)$. Increasing temperature causes more negative surface charges at the both oil/brine interface $\left(\zeta_{2}^{\prime}\right)$ and rock/brine interface $\left(\zeta_{1}^{\prime}\right)$, therefore more electrostatic repulsion exists when temperature increases and wettability shifts into more water-wet states. (b) Rock is positively charged in SW-4Ca $\left(\zeta_{1}\right)$ and also the charge at the oil/water interface is negative $\left(\zeta_{2}\right)$. Increasing temperature causes more negative surface charges at the oil/brine interface $\left(\zeta_{2}^{\prime}\right)$ and more positive surface charge at the rock/brine interface $\left(\zeta_{1}^{\prime}\right)$, therefore more electrostatic attraction exists when temperature increases and wettability shifts into more oil-wet states.

an increase in positive surface charges at the rock/brine interface in conjunction with an enhancement in negative surface charges at the oil/brine interface would result in collapsing the EDL due to the more electrostatic attraction between the interfaces (Fig. 5b) of SW-4Ca. It must be emphasized that the performance of SW at the elevated temperature was proved to be higher than SW-4S (0.97 vs. 0.93) which is in line with the zeta potential results and in agreement with a previous study [27] as well. Accordingly, it was observed that when temperature was increased from $28^{\circ} \mathrm{C}$ to $60^{\circ} \mathrm{C}$, the negative surface charges of dolomite particles in SW solution increased sharply by around $-15 \mathrm{mV}$, while the shift in negative zeta potential of $10 \mathrm{SW}$ and SW-4S was approximately -7 and $-10 \mathrm{mV}$, respectively. So, the spiky shift in negative surface charges for SW solution might generate a shock in rock/brine interface through which the EDL experiences greater electrostatic repulsion.

Now, the role of crude oil type on the wettability alteration of dolomite particles is examined through WSI measurements at ambient conditions. As mentioned earlier in Section 3.1, the contact angle results for crude-B with brines of different ionic content are provided in the supporting document (sf.3). Figure 6 shows the WSI for different SmWs and LS-SmWs when both crude-A and crude-B were utilized. This Figure shows two different trends. First, shifting from crude-A to crude-B contributes to an increase in WSI of SW, SW-4S, 10SW, and 10SW-4S towards more waterwet states. For example, the WSI of SW and SW-4S shifted from 0.18 and 0.48 for crude-A into 0.41 and 0.84 for crude-B. Again, the positive SmW and LS-SmW effects can be explained by the zeta potential results. It was found that crude-B is more strongly negatively charged at both ambient and elevated temperatures compared to crude-A. In addition, it was shown that the surface charges of dolomite particles in SW, SW-4S, and 10SW were entirely negative at ambient temperature and even more negative at elevated temperatures. Besides, changing crude oil type in a crude oil/brine/rock system, the interactions at the rock/brine interface remain quite unchanged, whilst the interactions at the oil/brine interface are completely influenced so that zeta potential shifts towards more negative values (Fig. 4). As a result, for crude-B, the surface charge at the rock/brine interface remains unchanged, but the oil/brine interface experiences more negative surface charges. Hence, the more electrostatic repulsion results in EDL expansion and consequently the wettability of dolomite rock shifts towards a less oil-wet or a more water-wet state (Fig. 7a) for SW, SW-4S, 10SW, and 10SW-4S. Second, as crude oil is changed from crude-A to crude-B, the SmW and LS-SmW effects become weakened when WSI of SW-4Ca, SW-4Mg, $10 \mathrm{SW}-4 \mathrm{Ca}$, and $10 \mathrm{SW}-4 \mathrm{Mg}$ fall drastically. For instance, the WSI of $10 \mathrm{SW}-4 \mathrm{Ca}$ and $10 \mathrm{SW}-$ $4 \mathrm{Mg}$ reduce from 0.71 and 0.30 to 0.31 and 0.17 , respectively. The reason can be found in zeta potential results, which showed that the zeta potential of dolomite particles in SW-4Ca and SW-4Mg were thoroughly positive. Again, the negative surface charges of crude-B are higher than 


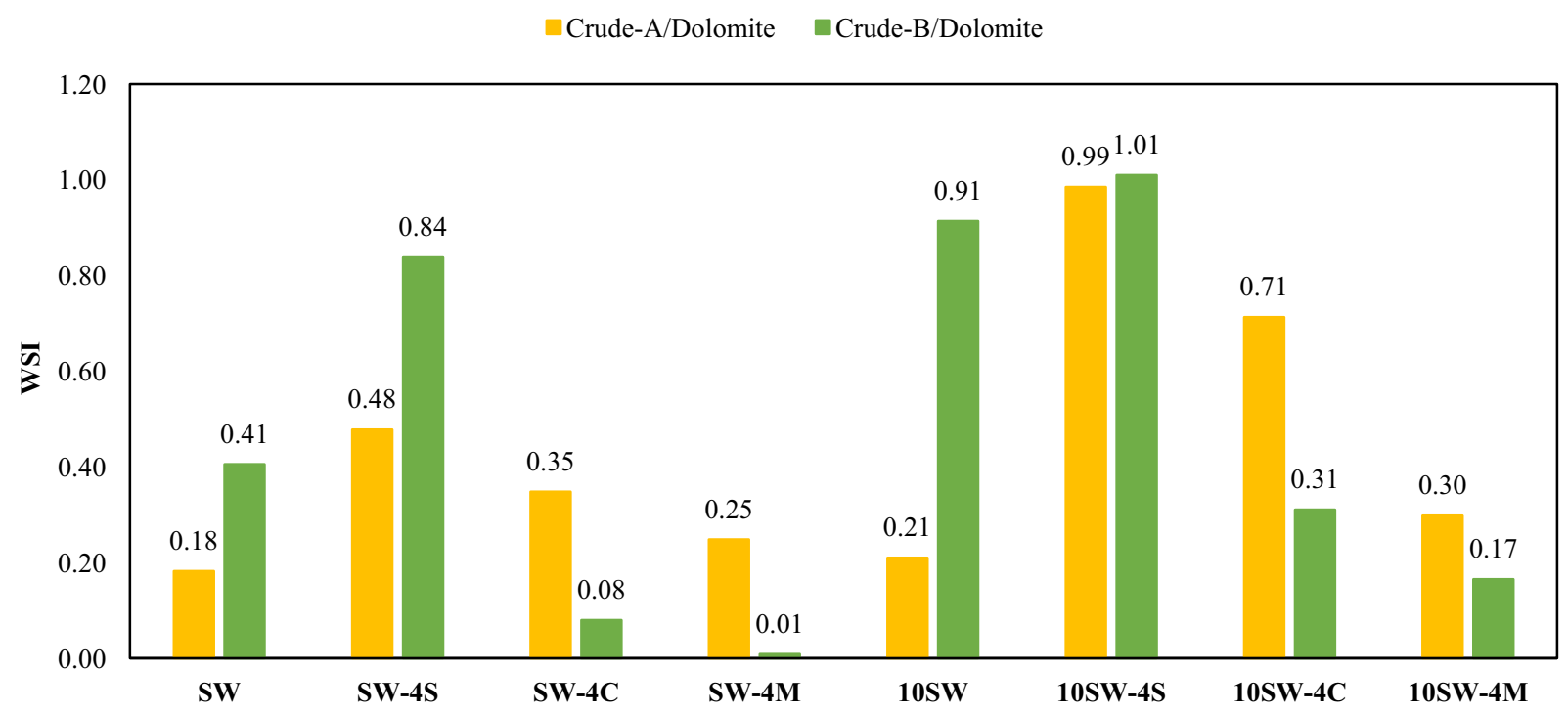

Fig. 6. Effect of crude oil type on the wettability state of dolomite particles, expressed in terms of WSI, for SmWs and LS-SmWs at ambient temperature and pressure $\left(28^{\circ} \mathrm{C}\right.$ and $\left.14.7 \mathrm{psi}\right)$.

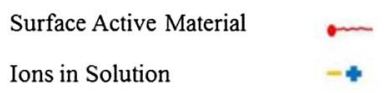

SW, 10SW,SW-4S, 10SW-4S

a
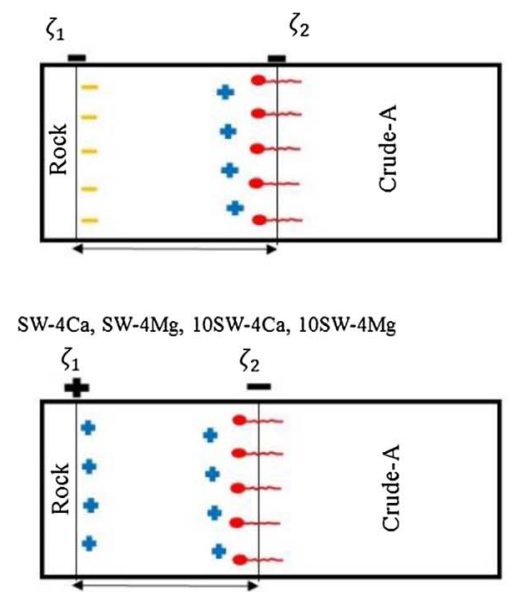
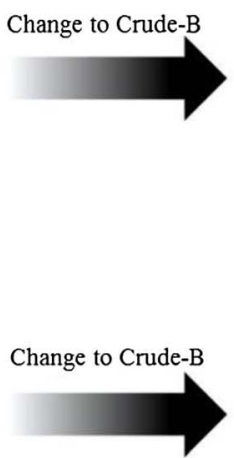

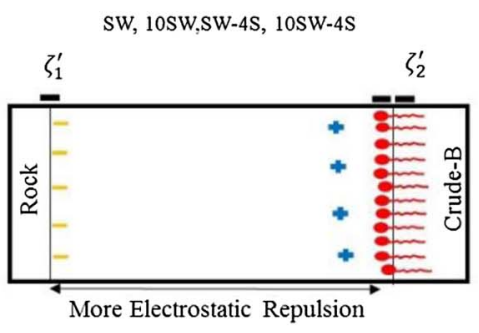

SW-4Ca, SW-4Mg, 10SW-4Ca, 10SW-4Mg

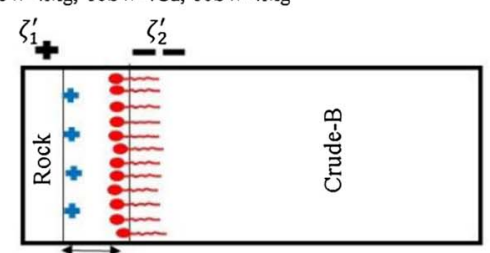

More Electrostatic Attraction

Fig. 7. The mechanism of wettability alteration through water injection, crude-oil effect (a) Rock is negatively charged in SW, 10SW, SW-4S, and 10SW-4S $\left(\zeta_{1}\right)$ and also the charge at the oil/brine interface is negative $\left(\zeta_{2}\right)$. Shifting to crude-B causes more negative surface charges at the oil/brine interface $\left(\zeta_{2}^{\prime}\right)$ while rock/brine interface $\left(\zeta_{1}^{\prime}\right)$ remains unchanged, therefore more electrostatic repulsion exists when crude-B is used and wettability shifts into more water-wet states. (b) Rock is positively charged in SW-4Ca, SW-4Mg, 10SW-4Ca, and $10 \mathrm{SW}-4 \mathrm{Mg}\left(\zeta_{1}\right)$, and also the charge at the oil/water interface is negative $\left(\zeta_{2}\right)$. Shifting to crude-B causes more negative surface charges at the oil/brine interface $\left(\zeta_{2}^{\prime}\right)$ whilst the charge at the rock/brine interface $\left(\zeta_{1}^{\prime}\right)$ remains constant, therefore more electrostatic attraction exists when crude-B is used and wettability shifts into more oil-wet states.

those of crude-A (oil/brine interface). Hence, for crude-B, the surface charges at the rock/brine interface remain constant and positive, but the surface charges at the oil/brine interface become more negative. Consequently, the EDL experiences more electrostatic attraction and gets collapsed when crude oil changes to crude-B (Fig. 7b).

\section{Conclusion}

In this study, the impact of the ionic content of injection water and temperature on wettability alteration were investigated through contact angle measurements. To validate the contact angle results, the zeta potentials of dolomite 
samples in SmWs at ambient and elevated temperatures were also measured. The most outstanding findings of this experimental study, which shed light on the underlying mechanism of wettability alteration during low salinity and modified water injection, are summarized below:

- It was shown that for LSW (10SW and SW), SmW (SW-4S), and LS-SmW (10SW-4S) injection, the EDL expansion due to an increase in electrostatic repulsion between rock/brine and oil/brine interfaces plays a very important role.

- Using wettability and zeta potential assessments, it was observed that $\mathrm{SO}_{4}^{2-}$ is the most effective ion involved in the wettability alteration mechanism during SmW injection.

- Adjusting the ion content of injection water at ambient temperature for low saline brines, such as 10SW, is more efficient than higher saline brines, like SW. However, our observations at elevated temperature suggest that improving the ionic content of high saline brines, like SW, is more effective than low saline brines. This notwithstanding, SW is the most efficient injection water receipt at elevated temperature not only based on technical observations such as wettability alteration response, but also based on the economical and easy method of preparation.

- The adsorption of ions which are already responsible for the rock surface charge at ambient temperature increases dramatically at elevated temperatures.

- Increase in temperature results in wettability shift into more water-wet states for dolomite samples when SW, 10 SW, SW-4S, and 10SW-4S are used. On the other side, the wettability of dolomite samples when SW-4Ca and 10SW-4Ca were utilized shifts towards more oil-wet states at higher temperatures.

- Crude oil composition can considerably affect the wettability alteration during $\mathrm{SmW}$ and LS-SmW injection. This is an area which needs more careful studies.

Acknowledgments. The authors deeply appreciate the Sharif EOR lab faculty for providing support to execute this study.

\section{Supplementary Material}

Supporting information (sf.1, sf.2, sf.3)

The Supporting information is available at https://ogst. ifpenergiesnouvelles.fr/10.2516/ogst/2019003/olm.

\section{References}

1 Strand S., Puntervold T., Austad T. (2008) Effect of temperature on enhanced oil recovery from mixed-wet chalk cores by spontaneous imbibition and forced displacement using seawater, Energy Fuels 22, 5, 3222-3225.

2 Yousef A.A., Al-Saleh S., Al-Kaabi A.U., Al-Jawfi M.S. (2010) Laboratory investigation of novel oil recovery method for carbonate reservoirs, Canadian Unconventional Resources and International Petroleum Conference, Society of Petroleum Engineers.

3 Yousef A.A., Liu J.S., Blanchard G.W., Al-Saleh S., Al-Zahrani T. (2012) Smart waterflooding: industry, SPE Annual Technical Conference and Exhibition, Society of Petroleum Engineers.

4 Al-Shalabi E.W., Sepehrnoori K., Pope G., Mohanty K. (2014) A fundamental model for predicting oil recovery due to low salinity water injection in carbonate rocks, SPE Energy Resources Conference, Society of Petroleum Engineers.

5 Tang G., Morrow N.R. (1997) Salinity, temperature, oil composition, and oil recovery by waterflooding, SPE Reserv. Eng. 12, 04, 269-276.

6 McGuire P., Chatham J., Paskvan F., Sommer D., Carini F. (2005) Low salinity oil recovery: An exciting new EOR opportunity for Alaska's North Slope, SPE Western Regional Meeting, Society of Petroleum Engineers.

7 Zhang Y., Morrow N.R. (2006) Comparison of secondary and tertiary recovery with change in injection brine composition for crude-oil/sandstone combinations, SPE/DOE Symposium on Improved Oil Recovery, Society of Petroleum Engineers.

8 Lager A., Webb K.J., Black C., Singleton M., Sorbie K.S. (2008) Low salinity oil recovery-an experimental investigation, Petrophysics 49, 01, 28-35.

9 Soraya B., Malick C., Philippe C., Bertin H.J., Hamon G. (2009) Oil recovery by low-salinity brine injection: laboratory results on outcrop and reservoir cores, SPE Annual Technical Conference and Exhibition, Society of Petroleum Engineers.

10 Ligthelm D.J., Gronsveld J., Hofman J., Brussee N., Marcelis F., van der Linde H. (2009) Novel waterflooding strategy by manipulation of injection brine composition, EUROPEC/ EAGE Conference and Exhibition, Society of Petroleum Engineers.

11 Austad T., RezaeiDoust A., Puntervold T. (2010) Chemical mechanism of low salinity water flooding in sandstone reservoirs, SPE Improved Oil Recovery Symposium, Society of Petroleum Engineers.

12 Berg S., Cense A., Jansen E., Bakker K. (2010) Direct experimental evidence of wettability modification by low salinity, Petrophysics 51, 05, 314-322.

13 Lee S., Webb K., Collins I., Lager A., Clarke S. (2011) Low salinity oil recovery-increasing understanding of the underlying mechanisms of double layer expansion, IOR 2011-16th European Symposium on Improved Oil Recovery, Cambridge, United Kingdom.

14 Vledder P., Gonzalez I.E., Carrera Fonseca J.C., Wells T., Ligthelm D.J. (2010) Low salinity water flooding: proof of wettability alteration on a field wide scale, SPE Improved Oil Recovery Symposium, Society of Petroleum Engineers.

15 Hassenkam T., Pedersen C.S., Dalby K., Austad T., Stipp S.L.S. (2011) Pore scale observation of low salinity effects on outcrop and oil reservoir sandstone, Colloids Surf. A: Physicochem. Eng. Aspects 390, 1, 179-188.

16 Mahani H., Sorop T., Ligthelm D.J., Brooks D., Vledder P., Mozahem F., Ali Y. (2011) Analysis of field responses to lowsalinity waterflooding in secondary and tertiary mode in Syria, SPE EUROPEC/EAGE Annual Conference and Exhibition, Society of Petroleum Engineers.

17 Nasralla R.A., Bataweel M.A., Nasr-El-Din H.A. (2013) Investigation of wettability alteration and oil-recovery improvement by low-salinity water in sandstone rock, $J$. Can. Pet. Technol. 52, 02, 144-154. 
18 Romero M.I., Gamage P., Jiang H., Chopping C., Thyne G. (2013) Study of low-salinity waterflooding for single-and two-phase experiments in Berea sandstone cores, J. Pet. Sci. Eng. 110, 149-154.

19 Alotaibi M.B., Azmy R., Nasr-El-Din H.A. (2010) Wettability challenges in carbonate reservoirs, SPE Improved Oil Recovery Symposium, Society of Petroleum Engineers.

20 Strand S., Høgnesen E.J., Austad T. (2006) Wettability alteration of carbonates-Effects of potential determining ions $\left(\mathrm{Ca}^{2+}\right.$ and $\left.\mathrm{SO}_{4}^{2-}\right)$ and temperature, Colloids Surf. A: Physicochem. Eng. Aspects 275, 1, 1-10.

21 Yousef A.A., Al-Saleh S.H., Al-Kaabi A., Al-Jawfi M.S. (2011) Laboratory investigation of the impact of injection-water salinity and ionic content on oil recovery from carbonate reservoirs, SPE Reserv. Eval. Eng. 14, 05, 578-593.

22 Sharma M., Filoco P. (2000) Effect of brine salinity and crude-oil properties on oil recovery and residual saturations, SPE J. 5, 03, 293-300.

23 Yildiz H.O., Morrow N.R. (1996) Effect of brine composition on recovery of Moutray crude oil by waterflooding, J. Pet. Sci. Eng. 14, 3-4, 159-168.

24 Austad T., Strand S., Høgnesen E., Zhang P. (2005) Seawater as IOR fluid in fractured chalk, SPE International Symposium on Oilfield Chemistry, Society of Petroleum Engineers.

25 Austad T., Shariatpanahi S., Strand S., Black C., Webb K. (2011) Conditions for a low-salinity enhanced oil recovery (EOR) effect in carbonate oil reservoirs, Energy Fuels 26, 1, 569-575.

26 Webb K.J., Black C.J.J., Tjetland G. (2005) A laboratory study investigating methods for improving oil recovery in carbonates, International Petroleum Technology Conference, International Petroleum Technology Conference.

27 Zhang P., Austad T. (2006) Wettability and oil recovery from carbonates: Effects of temperature and potential determining ions, Colloids Surf. A: Physicochem. Eng. Aspects 279, 1, 179-187.

28 Zhang P., Tweheyo M.T., Austad T. (2007) Wettability alteration and improved oil recovery by spontaneous imbibition of seawater into chalk: Impact of the potential determining ions $\mathrm{Ca}^{2+}, \mathrm{Mg}^{2+}$, and $\mathrm{SO}_{4}^{2-}$, Colloids Surf. A: Physicochem. Eng. Aspects 301, 1, 199-208.

29 Fernø M., Grønsdal R., Åsheim J., Nyheim A., Berge M., Graue A. (2011) Use of sulfate for water based enhanced oil recovery during spontaneous imbibition in chalk, Energy Fuels 25, 4, 1697-1706.

30 Gupta R., Smith G.G., Hu L., Willingham T., Lo Cascio M. (2011) Enhanced waterflood for carbonate reservoirs-impact of injection water composition, SPE Middle East Oil and Gas Show and Conference, Society of Petroleum Engineers.

31 Fathi S.J., Austad T., Strand S. (2011) Effect of waterextractable carboxylic acids in crude oil on wettability in carbonates, Energy Fuels 25, 6, 2587-2592.

32 Romanuka J., Hofman J., Ligthelm D.J., Suijkerbuijk B., Marcelis F., Oedai S. (2012) Low salinity EOR in carbonates, SPE Improved Oil Recovery Symposium, Society of Petroleum Engineers.

33 Yi Z., Sarma H.K. (2012) Improving waterflood recovery efficiency in carbonate reservoirs through salinity variations and ionic exchanges: a promising low-cost "smart-waterflood" approach, Abu Dhabi International Petroleum Conference and Exhibition, Society of Petroleum Engineers.

34 Al-Attar H.H., Mahmoud M.Y., Zekri A.Y., Almehaideb R., Ghannam M. (2013) Low-salinity flooding in a selected carbonate reservoir: experimental approach, J. Pet. Expl. Prod. Technol. 3, 2, 139-149.

35 Chandrasekhar S., Sharma H., Mohanty K.K. (2016) Wettability alteration with brine composition in high temperature carbonate rocks, SPE Annual Technical Conference and Exhibition, Society of Petroleum Engineers.

36 Kwak H.T., Yousef A.A., Al-Saleh S. (2014) New insights on the role of multivalent ions in water-carbonate rock interactions, SPE Improved Oil Recovery Symposium, Society of Petroleum Engineers.

37 Alotaibi M.B., Yousef A. (2017) The role of individual and combined ions in waterflooding carbonate reservoirs: Electrokinetic study, SPE Reserv. Eval. Eng. 20, 01, 77-86.

38 Mahani H., Keya A.L., Berg S., Bartels W.-B., Nasralla R., Rossen W.R. (2015) Insights into the mechanism of wettability alteration by low-salinity flooding (LSF) in carbonates, Energy Fuels 29, 3, 1352-1367.

39 Mahani H., Keya A.L., Berg S., Nasralla R. (2017) Electrokinetics of carbonate/brine interface in low-salinity waterflooding: Effect of brine salinity, composition, rock type, and $\mathrm{pH}$ on $\zeta$-potential and a surface-complexation model, SPE J. 22, 1, 53-68.

40 Myint P.C., Firoozabadi A. (2015) Thin liquid films in improved oil recovery from low-salinity brine, Curr. Opin. Colloid Interface Sci. 20, 2, 105-114.

41 Derjaguin B., Churaev N., Muller V. (1987) Wetting films, in surface forces, Springer, Boston, MA, pp. 327-367.

42 Hirasaki G. (1991) Wettability: Fundamentals and surface forces, SPE Form. Eval. 6, 02, 217-226.

43 Ramachandran R., Somasundaran P. (1986) Effect of temperature on the interfacial properties of silicates, Colloids Surf. 21, 355-369.

44 Rashid S., Mousapour M.S., Ayatollahi S., Vossoughi M., Beigy A.H. (2015) Wettability alteration in carbonates during "Smart Waterflood": Underlying mechanisms and the effect of individual ions, Colloids Surf. A: Physicochem. Eng. Aspects 487, 142-153.

45 Golabi E., Seyedeyn Azad F., Ayatollahi S., Hosseini N., Akhlaghi N. (2012) Experimental study of wettability alteration of limestone rock from oil wet to water wet by applying various surfactants, SPE Heavy Oil Conference Canada, Society of Petroleum Engineers.

46 Austad T. (2013) Water-based EOR in carbonates and sandstones: new chemical understanding of the EOR potential using smart water, Enhanc. Oil Recov. Field Case Stud. 301-335.

47 Rao D.N (1996) Wettability effects in thermal recovery operations, SPE/DOE Improved Oil Recovery Symposium, Society of Petroleum Engineers.

48 Amin S., Rega C.A., Jankevics H. (2012) Detection of viscoelasticity in aggregating dilute protein solutions through dynamic light scattering-based optical microrheology, Rheol. Acta 51, 4, 329-342.

49 Buckley J.S. (1996) Mechanisms and consequences of wettability alteration by crude oils, Heriot-Watt University, Edinburgh, United Kingdom. 